\title{
Influence of local and remote SST on North Atlantic tropical cyclone potential intensity
}

\author{
Suzana J. Camargo $\cdot$ Mingfang Ting • \\ Yochanan Kushnir
}

Received: 28 December 2011/Accepted: 17 September 2012/Published online: 6 October 2012

(C) Springer-Verlag Berlin Heidelberg 2012

\begin{abstract}
We examine the role of local and remote sea surface temperature (SST) on the tropical cyclone potential intensity in the North Atlantic using a suite of model simulations, while separating the impact of anthropogenic (external) forcing and the internal influence of Atlantic Multidecadal Variability. To enable the separation by SST region of influence we use an ensemble of global atmospheric climate model simulations forced with historical, 1856-2006 full global SSTs, and compare the results to two other simulations with historical SSTs confined to the tropical Atlantic and to the tropical Indian Ocean and Pacific. The effects of anthropogenic plus other external forcing and that of internal variability are separated by using a linear, "signal-to-noise" maximizing EOF analysis and by projecting the three model ensemble outputs onto the respective external forcing and internal variability time series. Consistent with previous results indicating a tampering influence of global tropical warming on the Atlantic hurricane potential intensity, our results show that nonlocal SST tends to reduce potential intensity associated with locally forced warming through changing the upper level atmospheric temperatures. Our results further indicate that the late twentieth Century increase in North Atlantic potential intensity, may not have been dominated by anthropogenic influence but rather by internal variability.
\end{abstract}

Keywords Sea surface temperature - Potential intensity · Hurricanes · Local and remote effects

S. J. Camargo $(\bowtie) \cdot$ M. Ting $\cdot$ Y. Kushnir

Lamont-Doherty Earth Observatory, Columbia University,

Palisades, NY 10964, USA

e-mail: suzana@1deo.columbia.edu

\section{Introduction}

Understanding and predicting variability and change in tropical cyclone activity (intensity and frequency) is a topic of great societal concern due to the potentially catastrophic impacts of these storms. As an example, the infamous Hurricane Katrina of 2005 appears to be the most costly natural disaster to strike the United States ever, and the deadliest since 1928 (Graumann et al. 2005), with total estimated damage exceeding 100 billion dollars and the death toll of more than 1,300 . It also resulted in a displacement of 250,000 people, a higher number than the Dust Bowl years of the 1930s (Graumann et al. 2005).

The relationship between ocean temperature and tropical cyclone activity (frequency and intensity) has long been noted in the literature. Warm local sea surface temperatures (SSTs) are a necessary condition for the formation and intensification of tropical cyclones (e.g. Palmén 1948; Gray 1968; 1979; Emanuel 1987). It is not entirely clear, however, how increasing SSTs in a warming world would influence tropical cyclone activity.

One measure of the relationship between SST and tropical cyclone activity is the potential intensity (PI; Emanuel 1986, 1988; Holland 1997), which is a theoretical concept that evaluates maximum intensity that a tropical cyclone could reach given the available thermodynamic energy for tropical cyclone intensification in the environment, including the underlying ocean. Although PI is strongly related to SST, it is also affected by the properties of the atmosphere. While there are caveats associated with PI theory (Smith et al. 2008; Montgomery et al. 2009) due to some of the simplifications made in its development, an alternative theory or measure of maximum theoretical intensity has not been fully developed. For instance, in a simplified axisymmetric framework, improvements of the 
model cannot be expressed in terms of environmental conditions only and therefore the latter cannot be used to predict a theoretical limit for the intensity for a given environment (Bryan and Rotunno 2009). That said, PI theory has been well validated with observations. For example, Wing et al. (2007) showed that observed interannual variations of maximum tropical cyclone intensity are consistent with PI predictions.

Theoretical studies predict an increase in tropical cyclone intensity in a warming world due to the increasing SSTs and the thermodynamic state of the atmosphere (Emanuel 1987; Holland 1997). However, Vecchi and Soden (2007) showed that there are regions where the PI decreases in model projections of the 21st century even though the tropical oceans warm everywhere. Vecchi and Soden (2007) argued that non-local SST could modify PI through their influence on upper atmospheric temperatures. Furthermore, Vecchi et al. (2008) discussed the fundamental importance of the remote SST contribution to the power dissipation index (PDI, Emanuel 2005) and indicated that it is the relative warming of the local SST with respect to the tropic-wide warming that determines the PDI trend. Extrapolating PDI projections based on relative and total SST leads to very different results for the 21st century than when considering only local effects. For the tropical Atlantic this happens because the local SSTs do not exhibit a substantial trend in the 21 st century relative to the entire tropics (Vecchi et al. 2008; Villarini and Vecchi 2012). Swanson (2008) argued further that there is no straightforward link between warmer SSTs in the so-called Atlantic main development region (MDR) and more intense tropical cyclones. More recently, Ramsay and Sobel (2011) used a single-column model to investigate the effects of the relative and absolute SST on the PI and concluded that the PI is more sensitive to relative SST than to absolute SST and they attributed this sensitivity primarily to larger changes in the air-sea disequilibrium as SST changes.

Sobel and Camargo (2012) analyzed various tropical environmental variables in the twenty-first century and examined their remaining "seasonal change" once the annual change is subtracted. Similar to other environmental variables, for the twenty-first century, seasonal PI increases in the summer hemisphere and decreases in the winter hemisphere compared to the present, following the SST seasonal changes. Since the annual mean is marked by relative warming in the Northern Hemisphere compared to the Southern Hemisphere, the twenty-first century projected seasonal PI opposes the annual mean change in January-March (JFM) and enhances the annual mean change in July-August (JAS).

The North Atlantic, including the MDR, is a region of intense decadal and longer time scale variability. The relationship between hurricane activity and internal modes of variability such as Atlantic Multidecadal Variability (AMV, also known as Atlantic Multidecadal OscillationAMO, e.g., Kushnir 1994; Enfield et al. 2001) has been the subject of various studies. The AMV is generally represented by the anomaly in SST averaged over the entire North Atlantic basin (Enfield et al. 2001) and as such assuming a tight connection between tropical and extratropical North Atlantic SST variability. Goldenberg et al. (2001) showed that there exists a positive relationship between the Atlantic hurricane activity and multi-decadal tropical Atlantic SSTs in the tropical storms MDR and that the latter is part of the basin pattern. This association was also stressed in Zhang and Delworth (2006). In contrast, Mann and Emanuel (2006) attributed the variability in the Atlantic tropical cyclone decadal variability during the late nineteenth and twentieth centuries primarily to the impact of anthropogenic forcing on MDR SSTs, including a regional cooling due to aerosol forcing between $\sim 1950$ and $~ 1970$. Ting et al. (2009) and DelSole et al. (2011) however, showed that while anthropogenic forcing plays an important role in the warming of tropical Atlantic SST, the natural, AMV related changes are separately distinguishable there. Others have shown a relation between the so-called Atlantic Meridional Mode (Servain 1991)—a phenomenon correlated with AMV-and interannual time scale variability in Atlantic tropical cyclone activity (Vimont and Kossin 2007; Kossin and Vimont 2007; Kossin et al. 2010).

The recent warming of North Atlantic SSTs (Fig. 1) and the documented importance of natural and anthropogenic forcing in this warming, call for an attempt to quantitatively distinguish between the roles of anthropogenic forcing and internal variability contributions to the PI trend in the region. The distinction between natural anthropogenic forcing in the climate system is fundamental for decadal predictability studies (Solomon et al. 2011). Moreover, it is also important in this context to determine the role of local and remote SST changes in determining PI changes.

To address these goals we use a set of long simulations of an atmospheric global climate model, forced with prescribed historical SSTs and examine the differences in PI between these simulations in the North Atlantic domain. In order to separate the role of the local (i.e., tropical Atlantic) SST from the remote SST forcing, we use primarily three different ensembles: in the first ensemble, the atmospheric model is forced with historical, time-varying global SSTs. The second ensemble is forced with SSTs varying only in the tropical Atlantic between $30^{\circ} \mathrm{S}$ and $30^{\circ} \mathrm{N}$ while elsewhere SSTs are kept at their climatological, monthly varying values. In the third ensemble only the tropical Atlantic SST has climatological values, while the tropical 
Fig. 1 Tropical North Atlantic MDR averaged SST (solid line), relative SST (dotted line) and tropical cyclone potential intensity (PI) (dashed line) computed using NCEP/NCAR reanalysis for the period 1950-2006. A 5-year running mean is applied to the annual value of June to November average hurricane season. The relative SST is defined as the difference of the SST and the zonal mean SST $\left(30^{\circ} \mathrm{S}-30^{\circ} \mathrm{N}\right)$ (Vecchi and Soden 2007). SST and relative SST are in ${ }^{\circ} \mathrm{C}$ and $\mathrm{PI}$ is shown in $\mathrm{m} / \mathrm{s}$

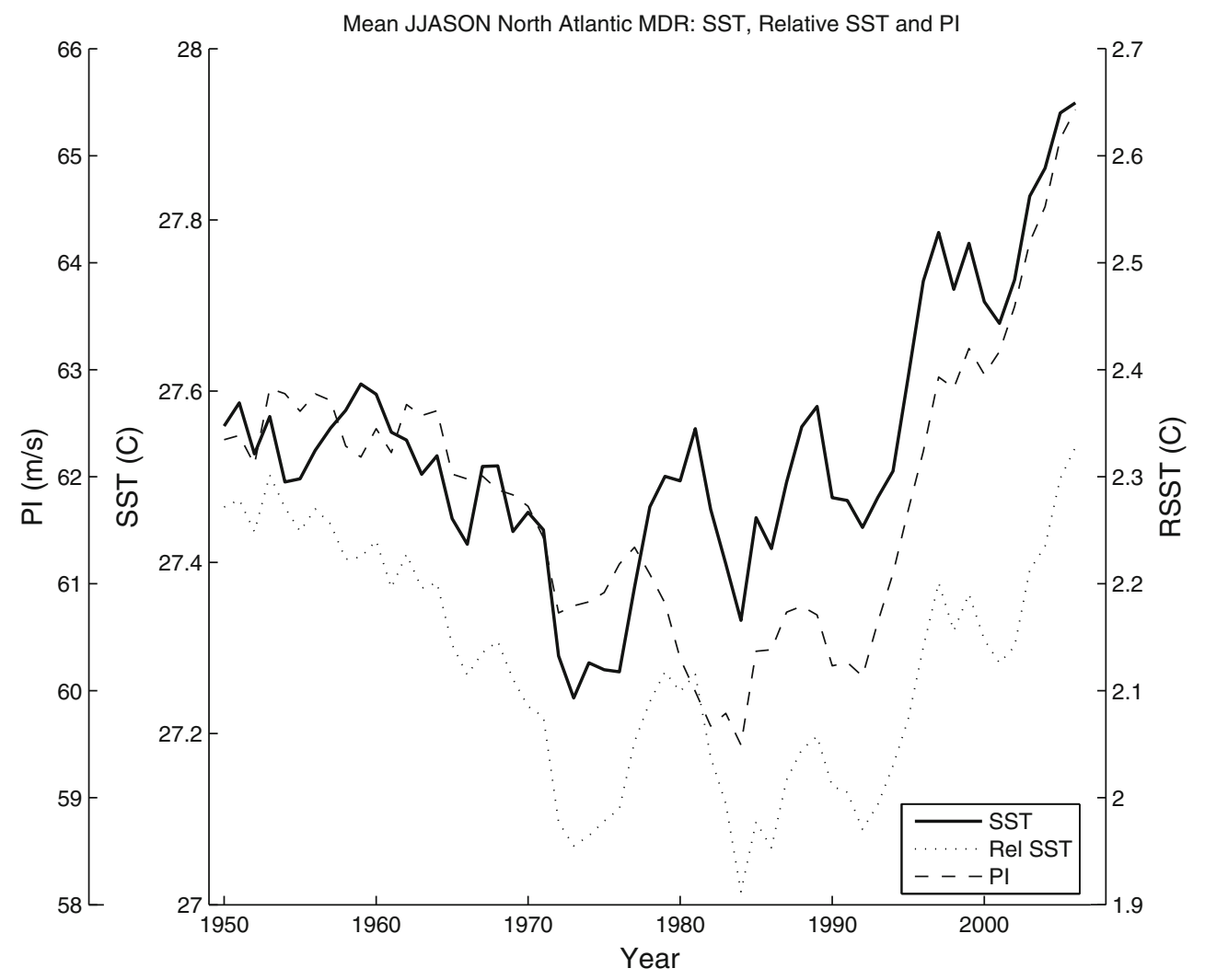

Indian and Pacific region SST varies. The varying SSTs are identical among these three cases, i.e. the tropical Atlantic SSTs in the simulation forced with that region only are the same SSTs as in the case of the global forced simulation, etc. By comparing the PI in these three sets of simulations, one can determine the role of the remote and local SST variability in the PI variability. These comparisons are not only done in the context of global warming, as in Vecchi and Soden (2007), but we also consider the role of local and external forcing in the case of the AMV. The latter roles are determined in a regression method as in Ting et al. (2009) and are explained in more details below.

In summary, our study will analyze the roles of relative and absolute SST in the PI of the tropical North Atlantic and their separate contribution in natural, AMV-related and anthropogenic changes.

A caveat to keep in mind is that we focus here on PI variations in the tropical Atlantic basin as a whole and in the Atlantic MDR, i.e. the ambient PI, the potential intensity theory is actually defined by the local thermodynamics conditions that surround a storm. The importance of the local storm PI variability instead of basin wide PI variability, is that on interannual to decadal time-scales, the local PI is sensitive to hurricane track variability in addition to changes in the ambient PI (Wing et al. 2007). Furthermore, Kossin and Camargo (2009) showed that while the local storm environmental conditions have the same variability and secular trends as that of the tropical mean environment, when we consider track variability the regional trend signal in PI is significantly reduced.

The paper is divided as follows. In Sect. 2 we describe the model simulations and data used in our analysis. The model PI in the Atlantic is compared with reanalysis PI over the same region in Sect. 3. The main results on forced and natural variability of PI are presented in the next section followed by the Summary.

\section{Data and model simulations}

We analyze various simulations of the NCAR Community Climate Model, version 3 (CCM3) run at T42 resolution with 18 vertical levels (Kiehl et al. 1998). The model was run with prescribed historical SST (globally or in individual ocean basins) from 1856 to the present. These simulations have been used in various studies focusing on SST-climate relationship (Seager et al. 2005, 2008; Seager 2007 and Kushnir et al. 2010). In addition, we included here a new simulation, to complement these previous ones (see below). We consider three different experiments, two with 16 and one with 8 ensemble members, with each member starting from a slightly different initial atmospheric state (see Seager et al. 2005 for further explanation). Each experiment was forced with time-varying, 
historical, monthly SSTs, using a merge between the Kaplan SST analysis (Kaplan et al. 1998) and the Hadley Center HadISST (Rayner et al. 2003). More details on the merging of these two products are given in Seager et al. (2005).

The three sets of CCM3 ensemble use SSTs prescribed in three different parts of the global ocean, following the concepts first introduced in Lau and Nath (1994). The first ensemble was forced with SSTs prescribed globally and is referred to as the Global Ocean Global Atmosphere (GOGA) ensemble. The second ensemble was forced with time-varying SSTs prescribed only in the tropical Atlantic domain $\left(30^{\circ} \mathrm{S}-30^{\circ} \mathrm{N}\right)$ while a repeated, climatological annual SST cycle was prescribed everywhere else; this ensemble is referred to as the Tropical Atlantic Global Atmosphere (TAGA) ensemble. The third and new ensemble was forced with time-varying SSTs in the tropical $\left(30^{\circ} \mathrm{S}-30^{\circ} \mathrm{N}\right)$ Indian and Pacific Oceans, between Africa and South America, with climatological SST prescribed everywhere else; this ensemble is referred to as Indian Ocean Pacific Ocean Global Atmosphere (IOPOGA) ensemble.

To further understand our results, a set of idealized simulations, with fixed patterns of SST anomalies, different from one another, were also used with the same CCM3 model. Here the prescribed fixed SST anomalies corresponded to the leading patterns of SST variability in the Atlantic during 1901-2004 as derived in a rotated EOF analysis by Schubert et al. (2009), where these simulations are further discussed. Specifically, the prescribed SST fields in these integrations corresponded to a climatological ocean to which an anomaly pattern corresponding to the warm or cold phase of the AMV was added. These integrations extended through 50 repeated annual cycles.

The PI was calculated using the formulation developed by Emanuel in a series of papers (Emanuel 1988, 1995; Bister and Emanuel 1998, 2002a, b) applied to the CCM3 model output. A brief description of the method for PI calculation can be found in the appendix of Camargo et al. (2007). We first calculate the PI for each of the ensemble members and then average to obtain the PI for the ensemble mean of each case. We also calculated the PI using the atmospheric data from the NCEP/NCAR Reanalysis (Kalnay et al. 1996; Kistler et al. 2001), ERA40 Reanalysis (Uppala et al. 2005) and ERA-Interim Reanalysis (ERA-Interim 2011), but with the same SSTs and horizontal resolution as in the GOGA simulations. The reason for using the GOGA run SST dataset and horizontal resolution of the NCEP/NCAR Reanalysis was to exclude a possible source of differences among the PI fields calculated from the various reanalysis datasets. It is important to note that these reanalysis datasets cover different time intervals, the NCEP/NCAR from 1948 to 2010, the ERA40 from September 1957 to August 2002, and the ERA-
Interim Reanalysis from 1989 to 2009. The figures comparing anomalies between reanalysis and model fields are calculated with respect to the climatologies during the time interval common to all of them, i.e., for the years 1989-2001.

The indices for the AMV and externally forced anthropogenic change used in the present analysis were obtained as in Ting et al. (2009). The methodology for deriving these indices is based on the linear method of the so-called Signal-to-Noise Maximizing EOF analysis, where IPCC fourth Assessment models are used to determine the forced signal and the AMV time series is calculated as a residual (see Ting et al. 2009). These indices are extended here for the period 1900-2006.

\section{Results}

\subsection{Potential intensity in the model and reanalysis}

We first compare the PI calculated from CCM3 model GOGA simulation and that from the 3 reanalysis products for the common period of 1989-2001. Figure 2 shows the annual maximum climatological patterns of PI for the GOGA ensemble mean and the 3 reanalyses, i.e. the maximum value of the climatological PI in each grid point. The general patterns of the PI, with maxima over the Indian Ocean and western tropical Pacific, are very similar for CCM3 and all three reanalysis. While the PI values of the GOGA ensemble mean simulation are somewhat higher than both the NCEP and ERA-40 reanalysis, they are similar to the ERA-Interim reanalysis. Furthermore, while in all three reanalysis there is a minimum of PI at the eastern equatorial Pacific, this minimum is much less pronounced for GOGA.

Because we are mainly interested in the North Atlantic, we compare in Fig. 3 the three reanalysis and the GOGA ensemble mean in that basin. Plotted are the mean PI values in June-November (JJASON, the Atlantic hurricane season). The GOGA PI pattern is very similar to those of the reanalysis, with closer agreement to the ERA-Interim reanalysis compared to the other two datasets. Maximum climatological PI values of over $70 \mathrm{~m} / \mathrm{s}$ are found in the Caribbean, Gulf of Mexico and the MDR, which includes the Caribbean and Atlantic Ocean between $9^{\circ} \mathrm{N}$ and $21.5^{\circ} \mathrm{N}$ (Goldenberg et al. 2001). As latitude increases, PI decreases, with the steepest gradient occurring in the eastern part of the basin.

The interannual variability of the PI in the MDR is shown in Fig. 4. The figure displays the anomalous PI averaged over the MDR during the JJASON hurricane season, between 1860 and 2006 (panel (a)), as depicted by the GOGA ensemble mean and by the corresponding 
(a) GOGA

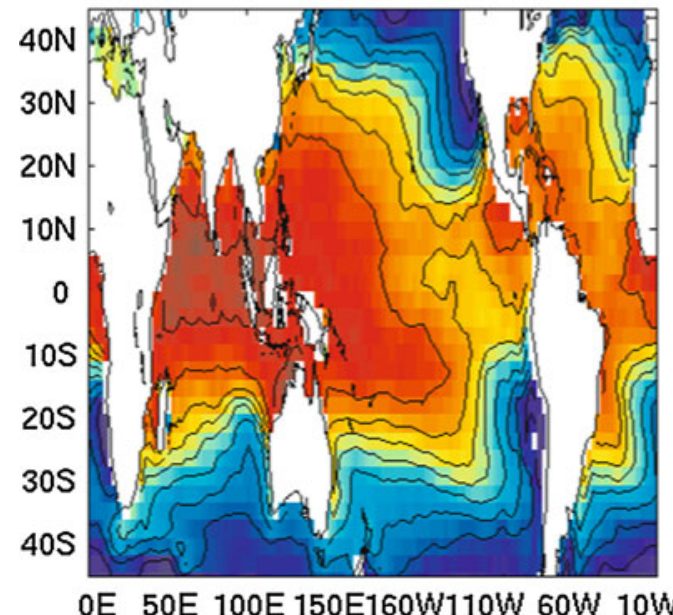

(c) ERA40 Rean.

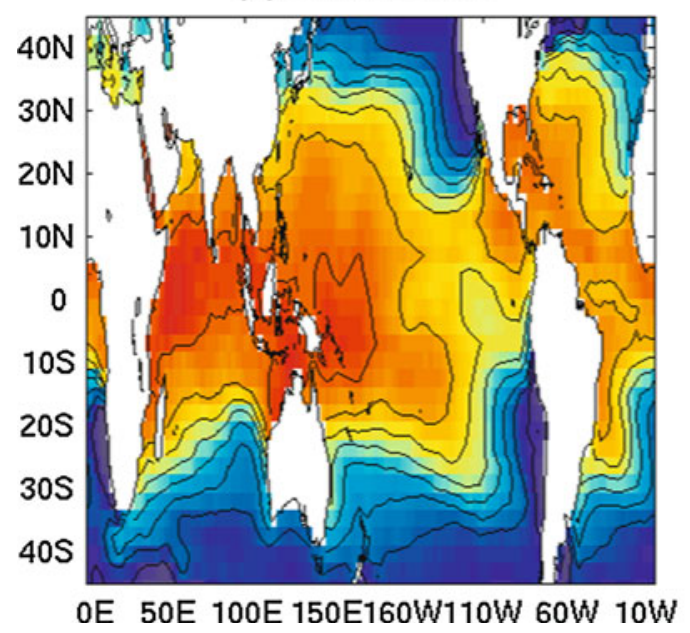

(b) NCEP Rean.

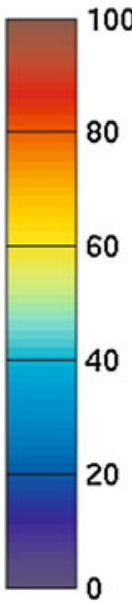

100

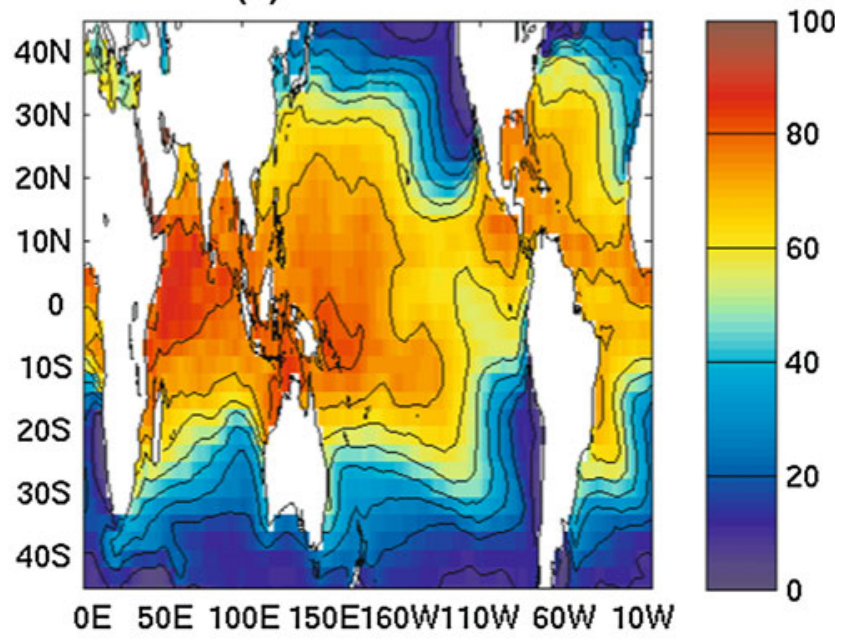

(d) Interim ECMWF Rean.

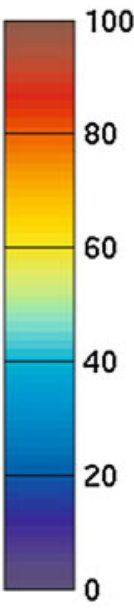

100

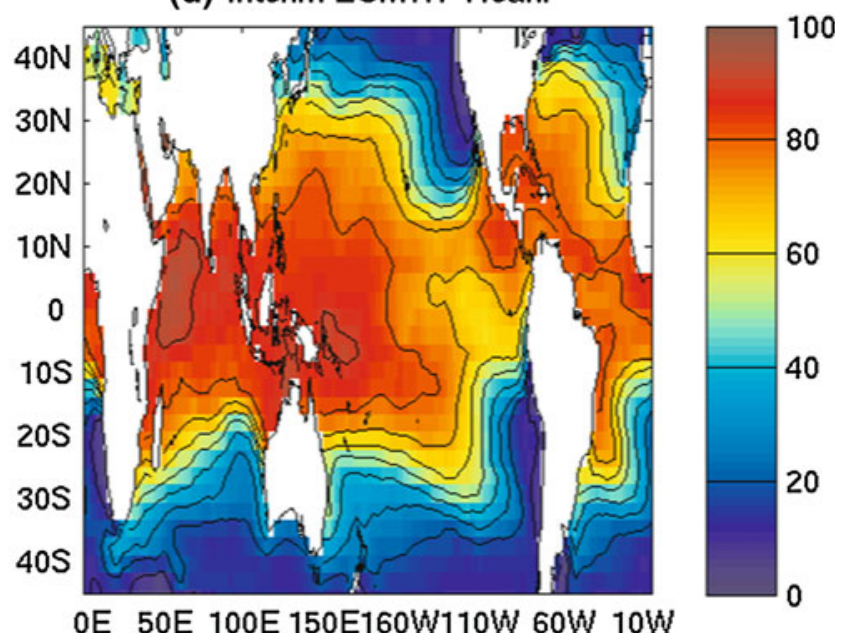

Fig. 2 Annual maximum of climatological PI (m/s) for a ensemble mean GOGA, b NCEP reanalysis, c ERA-40 reanalysis, d ERA-Interim reanalysis (common period 1989-2001)

reanalysis (the years of overlap between the model and reanalysis are plotted also separately in panel (b)). The correlations between the reanalysis and the ensemble mean PI for GOGA over the Atlantic MDR are shown in Table 1. The GOGA ensemble mean exhibits a significant (at the $5 \%$ level) correlation with all three reanalyses during the respective (and differing) overlap years. The highest correlation (0.92) is between GOGA and ERA-Interim and ERA40, for the years 1989-2006 and 1989-2001, respectively.

\subsection{Comparison of GOGA, TAGA and IOPOGA simulations}

By comparing the PI calculated from the GOGA, TAGA and IOPOGA experiments, we can readily separate the contribution to PI due to atmospheric response to tropical Atlantic SST and that due to atmospheric response to the
SST in the tropical Indian and Pacific region, i.e. the remote SST contribution. Figure 5a, c, e show the PI climatology in the tropical Atlantic during the peak hurricane season August-October (ASO), for the GOGA, TAGA and IOPOGA ensembles, respectively. The differences between the GOGA and TAGA runs (GOGA-TAGA), GOGA and IOPOGA, TAGA and IOPOGA during ASO are shown in Fig. 5b, d, e, respectively. In general, the climatological PI values are smaller in the GOGA than in the TAGA simulation (Fig. 5b), showing that remote SST forcing causes a reduction in tropical Atlantic PI values. The largest differences in GOGA and TAGA PI are found in the tropical North Atlantic east of the Caribbean and the tropical South Atlantic in the Northeast coast of Brazil. There are a few grid points in the Caribbean that show slight increases in PI in TAGA compared to GOGA in ASO. On the other hand, the difference of GOGA and IOPOGA PI climatologies is 
(a) GOGA

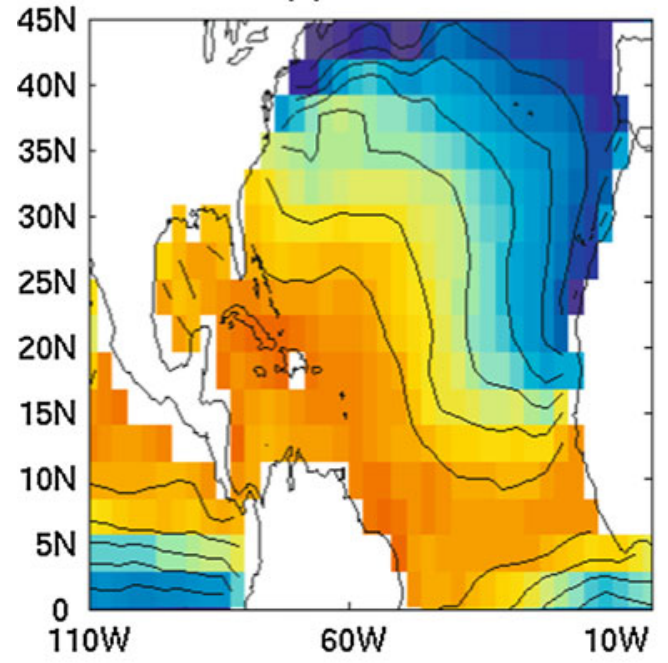

(c) ERA40 Rean.

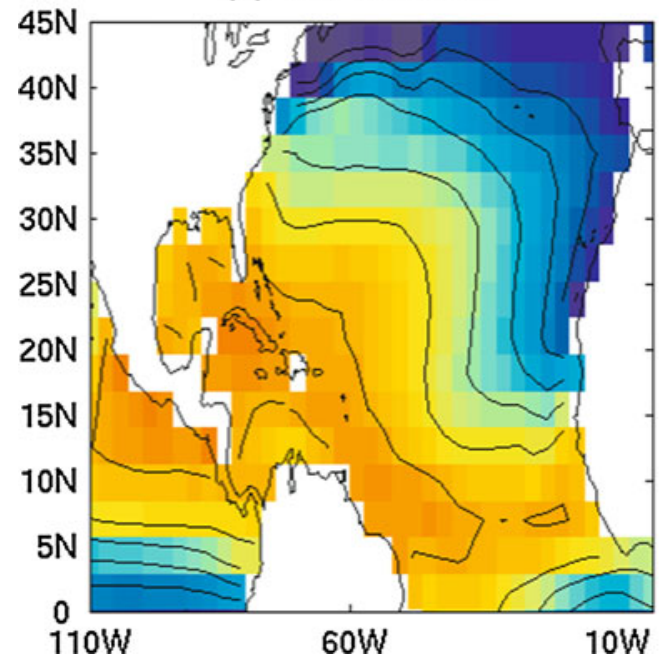

(b) NCEP Rean.
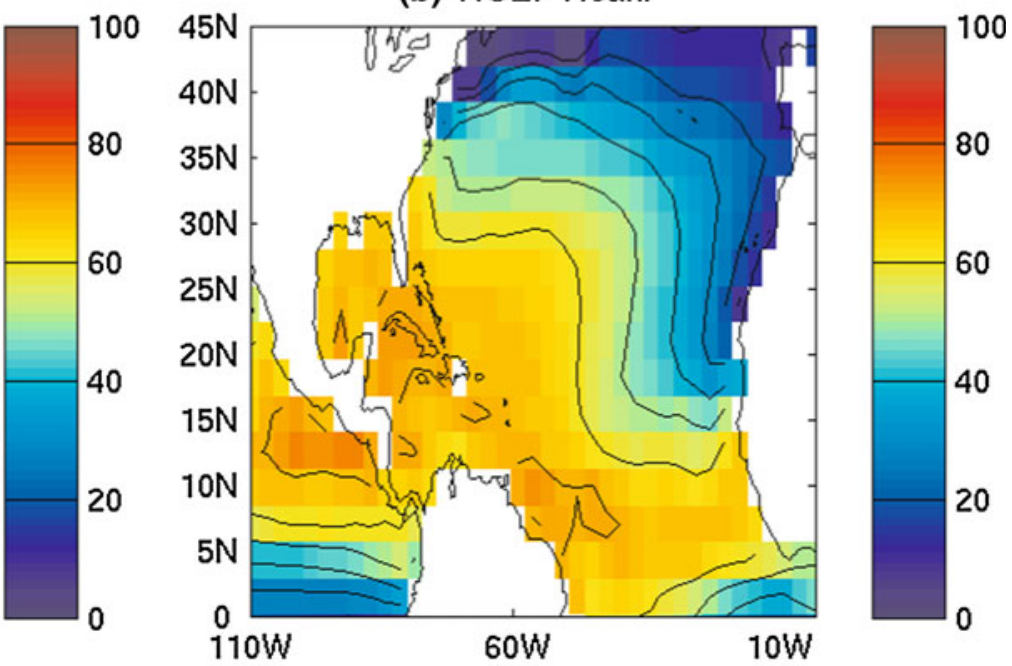

(d) Interim ECMWF Rean,

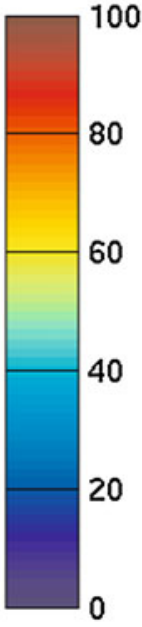

100

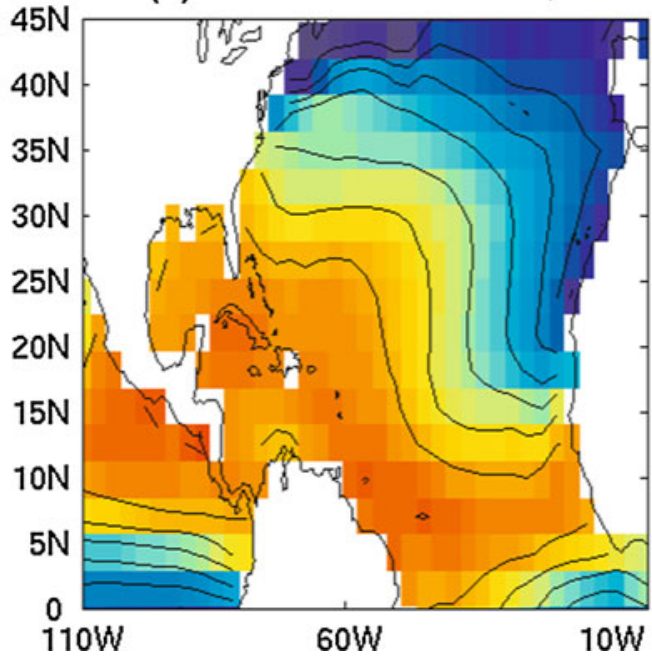

Fig. 3 June-November (JJASON) PI (m/s) over the North Atlantic for the common period 1989-2001 for the a ensemble mean GOGA, b NCEP reanalysis, c ERA-40 reanalysis, d Interim ECMWF reanalysis

noisier, with positive and negative values spread across the Atlantic, so that when integrated for the whole basin, the difference in the GOGA and IOPOGA climatologies is small.

The influence of remote SST variability is also evident in Fig. 6a, which shows the anomalous (with respect to the 1856-2006 climatology) ASO PI for the GOGA, TAGA and IOPOGA simulations averaged in the tropical North Atlantic $\left(0-30^{\circ} \mathrm{N}\right)$. The figure clearly shows that both GOGA and TAGA exhibit a positive trend as well as multidecadal variability during this period, with the TAGA PI trend and amplitude of variability larger than that in GOGA. In contrast, the IOPOGA simulation has a negative trend and little multidecadal variability. The different temporal variation between GOGA, TAGA and the IOPOGA is consistent with the relative SST of the tropical North Atlantic with respect to the tropical-wide mean SST, as shown in Fig. 6b. The close relation between the PI and relative SST confirms the results of Vecchi and Soden (2007), which considered relative SST as a very good proxy for PI. When the local SST warms (cools) more than the tropical mean, i.e., the relative SST increases (decreases), and PI increases (decreases).

Previous studies (Sobel et al. 2002; Tang and Neelin 1994) pointed out that the remote SST could influence the Atlantic PI through responses of the free-tropospheric temperature to remote SST changes. A warming of SST in remote tropical locations relative to the local SST leads to a larger warming of the upper tropospheric temperature relative to the local effect alone and consequently to the stabilization of the local atmosphere. The latter leads to a decrease in the local PI. Figure 7 shows the correlations of anomalous PI and $300 \mathrm{hPa}$ 
Fig. 4 Mean anomalous PI $(\mathrm{m} / \mathrm{s})$ in the North Atlantic MDR per JJASON season in the GOGA ensemble mean and reanalysis: 1856-2006 (top panel), zooming on the period 1950-2006 (bottom panel)
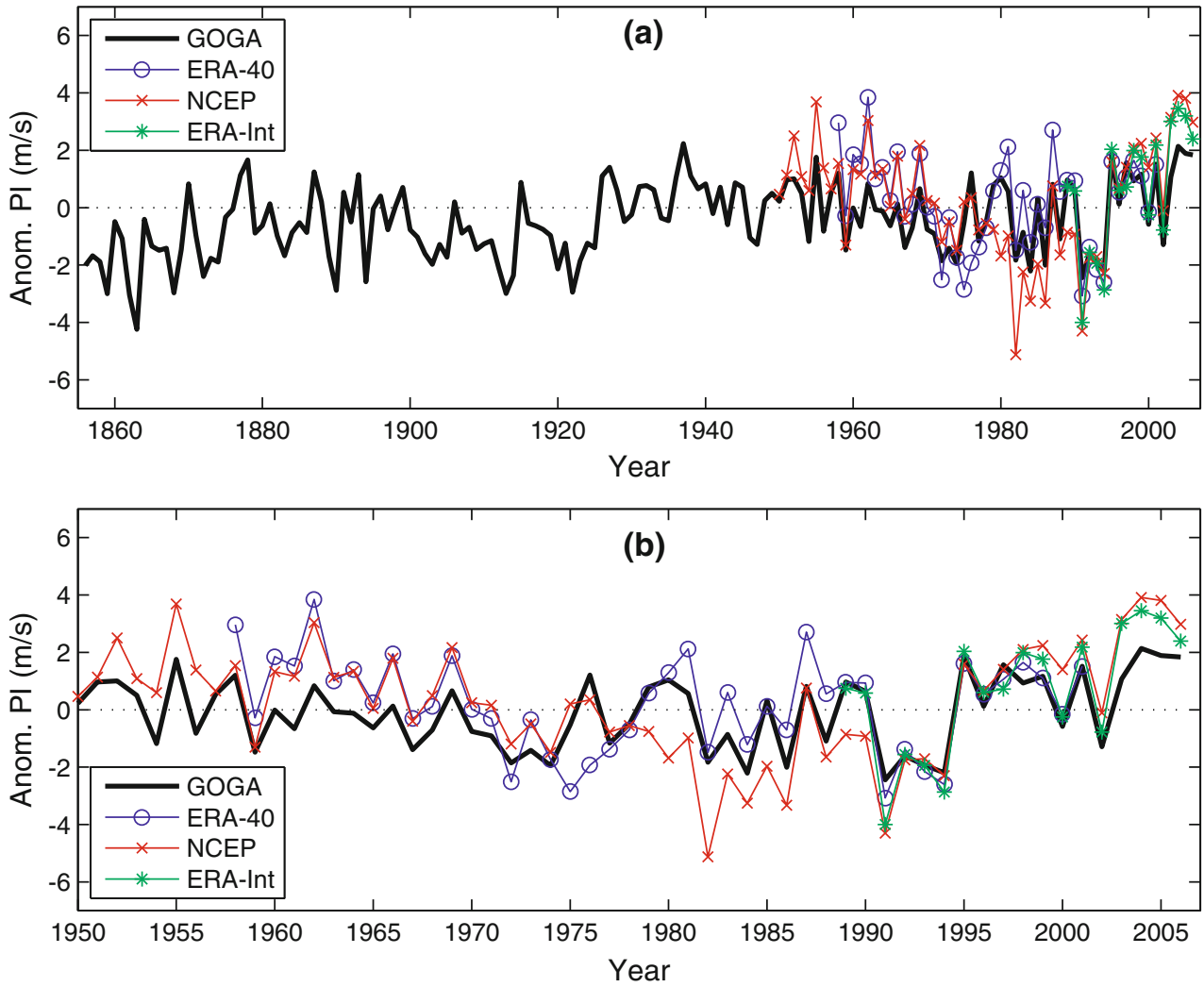

Table 1 Correlations of ensemble PI in the North Atlantic MDR in GOGA and the 3 reanalysis for ASO and JJASON in different timeperiods

\begin{tabular}{|c|c|c|c|c|c|c|}
\hline \multirow[t]{2}{*}{ Years } & \multicolumn{2}{|c|}{ NCEP } & \multicolumn{2}{|c|}{ ERA40 } & \multicolumn{2}{|c|}{ ERA-Interim } \\
\hline & ASO & JJASON & ASO & JJASON & ASO & JJASON \\
\hline 1950-2006 & 0.65 & 0.71 & & & & \\
\hline 1958-2001 & 0.57 & 0.68 & 0.48 & 0.61 & & \\
\hline 1989-2001 & 0.70 & 0.79 & 0.80 & 0.92 & 0.83 & 0.91 \\
\hline 1989-2006 & 0.70 & 0.78 & & & 0.86 & 0.92 \\
\hline
\end{tabular}

temperature over the tropical Atlantic region with the relative SST index (green line in Fig. 6b) using IOPOGA. Note that in the IOPOGA ensemble, the anomaly in relative SST is simply the negative of anomalous SST averaged in the IOPOGA prescribed region. Over most of the tropical Atlantic, the $300 \mathrm{hPa}$ temperature (Fig. 7b) is largely negatively correlated with the relative SST, consistent with the observed, gradual rise of SST in the IOPOGA region warming the upper tropospheric temperature in the tropical Atlantic. Consistently, the tropical Atlantic PI exhibits the opposite phase correlation (Fig. 7a) indicative of a PI decrease over most of the tropical Atlantic. The only exception is the Gulf of Mexico and the Caribbean region, where remote SST warming induced a cooling of the upper tropospheric temperatures and enhancement of PI. The calculation in Fig. 7 explains the difference between TAGA and IOPOGA PI shown in Fig. 5f.
In addition to the upward trend seen in both GOGA and TAGA Tropical North Atlantic PIs, the time series (Fig. 6) also exhibit a multi-decadal oscillation. This is particularly clear in the early part of the record, where higher PI values are seen between 1870 and 1895 compared to lower values in between 1990 and 1920. The same behavior is obtained if the averaging is conducted over the MDR region only (not shown). In the next subsection, we separate between the century-long upward PI trends and the multidecadal variability in the model simulation, relating the latter to the AMV, and examine the influence of local versus remote SST in both cases.

\subsection{AMV and Climate Change Influences on Atlantic PI}

In order to distinguish between the pattern of PI change that is arguably attributable to the monotonous increase of 
(a) GOGA PI ASO

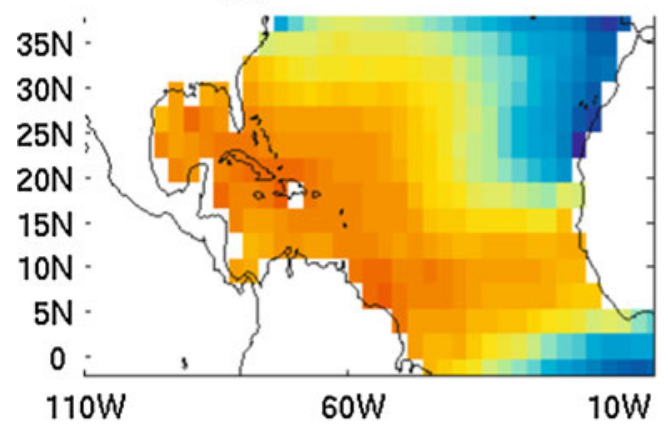

(c) TAGA PI ASO

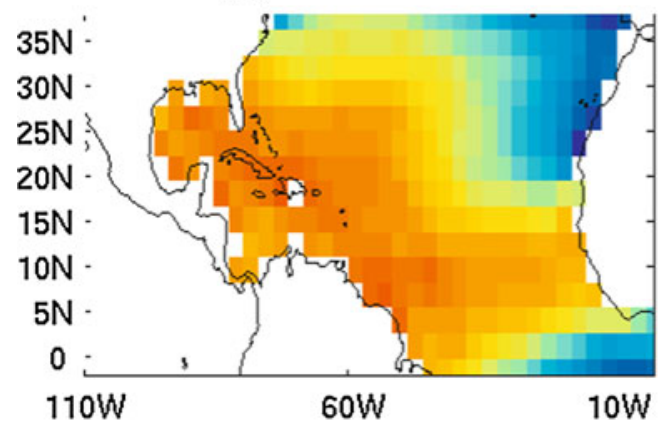

(e) IOPOGA PI ASO

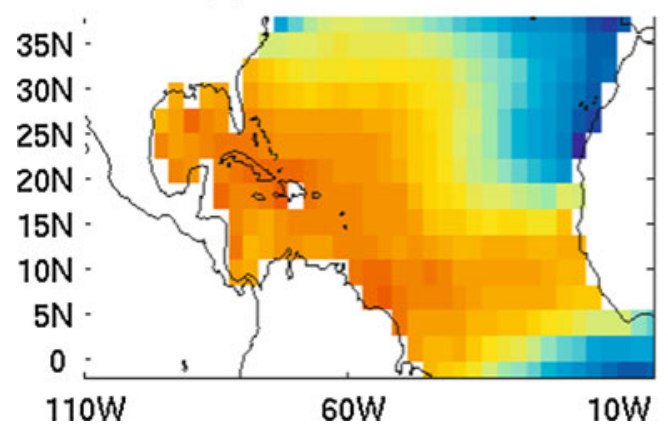

Fig. 5 Ensemble mean climatological (1856-2006) PI (m/s) for the peak hurricane season ASO in the tropical Atlantic for a GOGA, c TAGA, and e IOPOGA simulations. Differences between climatological PI in

external radiative forcing (hereafter $\mathrm{CC}$ for "climate change") and the pattern that is due to the internal climate variability associated with AMV, we first derived Atlantic SST CC and AMV indices as in Ting et al. (2009) for the years 1900-2006 and for the JJASON seasonal mean (Fig. 8a). The CC index displays a monotonic although not linear increase in time, whereas the AMV displays visible multi-decadal fluctuations. The linear regressions of global SST at each grid point with the AMV and CC indices are shown in Fig. 8b, c, respectively. The global patterns are similar to those shown in Ting et al. (2009), the warming signals associated with climate change present in most of the global oceans (Fig. 8b), while the AMV influence is concentrated in the North Atlantic, with weak warming in (b) Diff. GOGA \& TAGA PI ASO

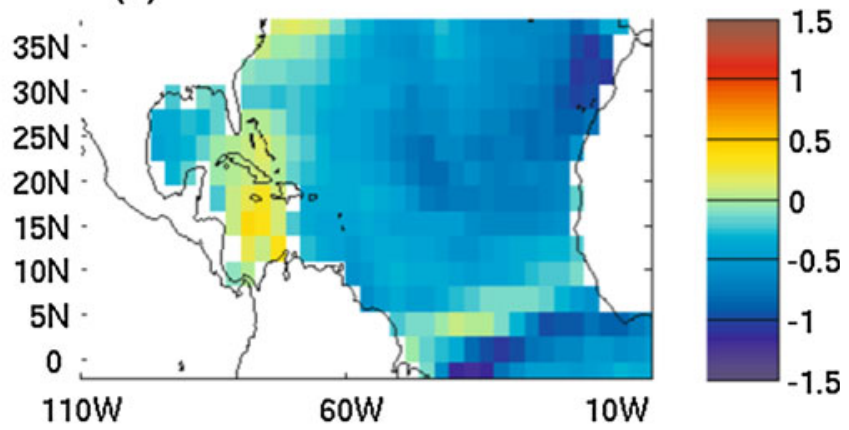

(d) Diff. GOGA \& IOPOGA PI ASO

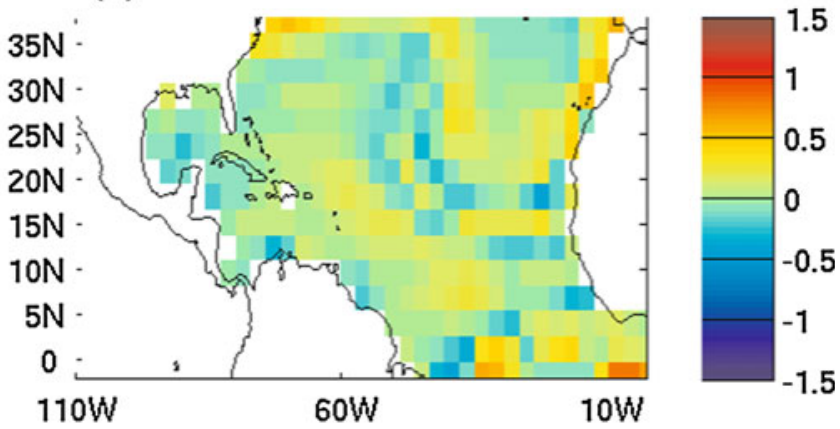

(f) Diff. TAGA \& IOPOGA PI ASO

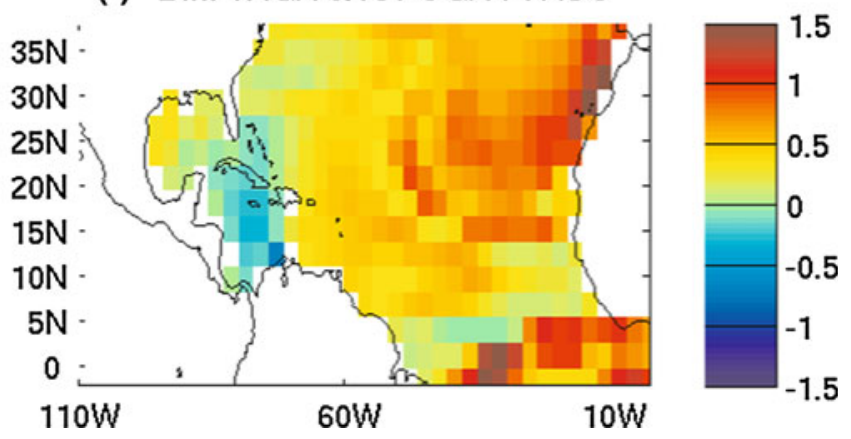

ASO for b GOGA and TAGA, $\mathbf{d}$ GOGA and IOPOGA, e TAGA and IOPOGA

$\mathrm{NH}$ and cooling in $\mathrm{SH}$ of the other ocean basins associated with the warm AMV phase (Fig. 8b).

We now regress the seasonal PI anomalies at each spatial grid point onto the CC and AMV indices to obtain the PI associated with these variations. Note that the regression is performed on seasonal PI values and that we do not show the regression of individual environmental variables that are part of the PI calculation. The spatial pattern of the regression coefficients (in $\mathrm{m} / \mathrm{s}$ per ${ }^{\circ} \mathrm{C}$ ) for GOGA, TAGA and IOPOGA are shown in Fig. 9.

In both GOGA and TAGA (Fig. 9a, c), the variation in tropical Atlantic PI associated with the positive phase of AMV, displays a consistent relationship to the corresponding SST anomaly pattern (Fig. 8b) with maximum PI 
Fig. 6 Mean anomalous (1856-2006 climatology subtracted) a PI $(\mathrm{m} / \mathrm{s})$, b relative SST (difference of local SST and mean tropical SST) in the tropical North Atlantic in ASO. GOGA is shown in blue, TAGA in red, and IOPOGA in green, with the thicker curves showing the smoothed 5-year mean time series

Fig. 7 Correlations of anomalous PI (a) and anomalous $300 \mathrm{hPa}$ temperature (b) with anomalous relative SST in the IOPOGA simulation (a) Mean Anom. PI Tropical North Atlantic

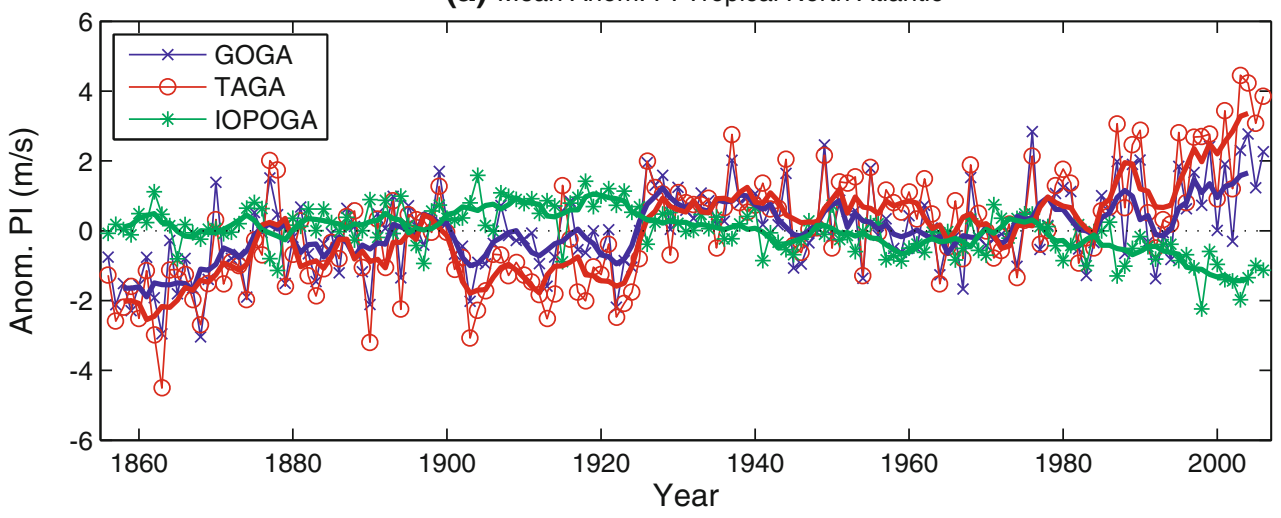

(b) Mean Anom. Relative SST Tropical North Atlantic

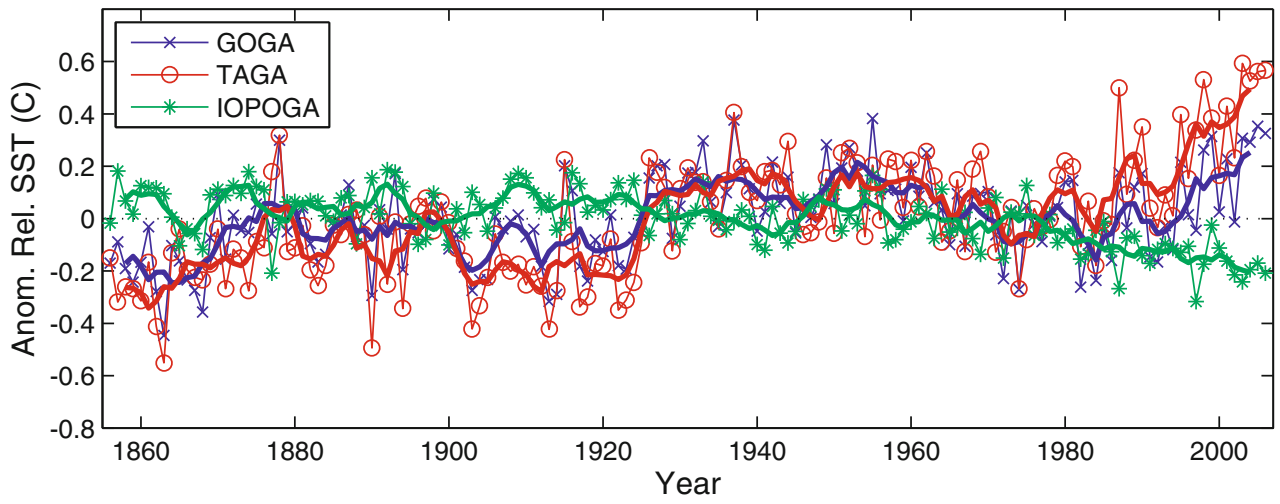

(a) Rel. SST \& PI - IOPOGA

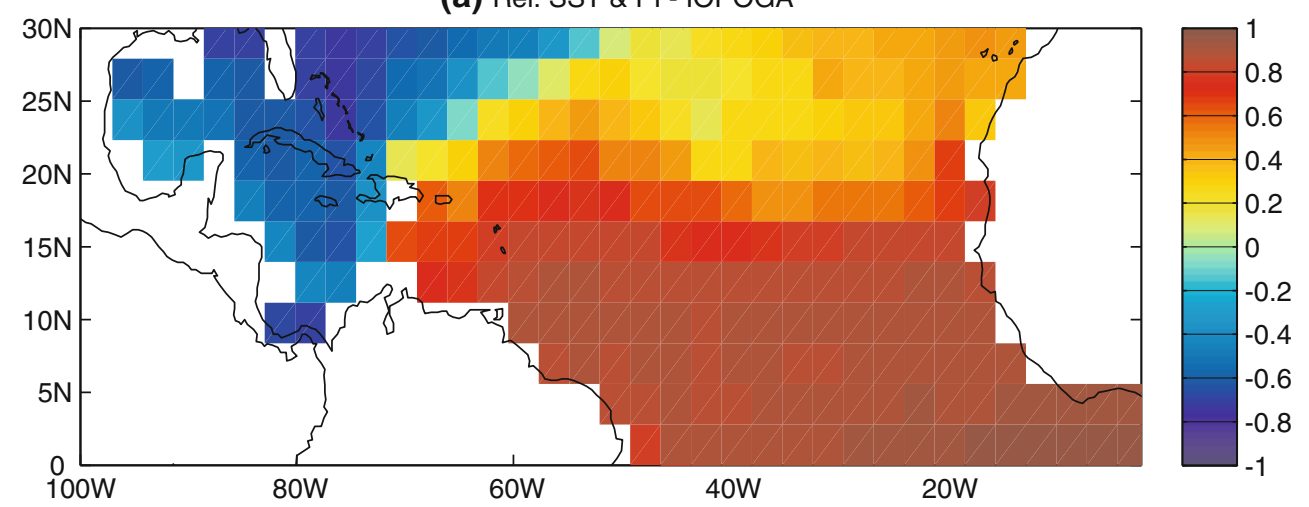

(b) Rel. SST \& Temp. 300hPa - IOPOGA

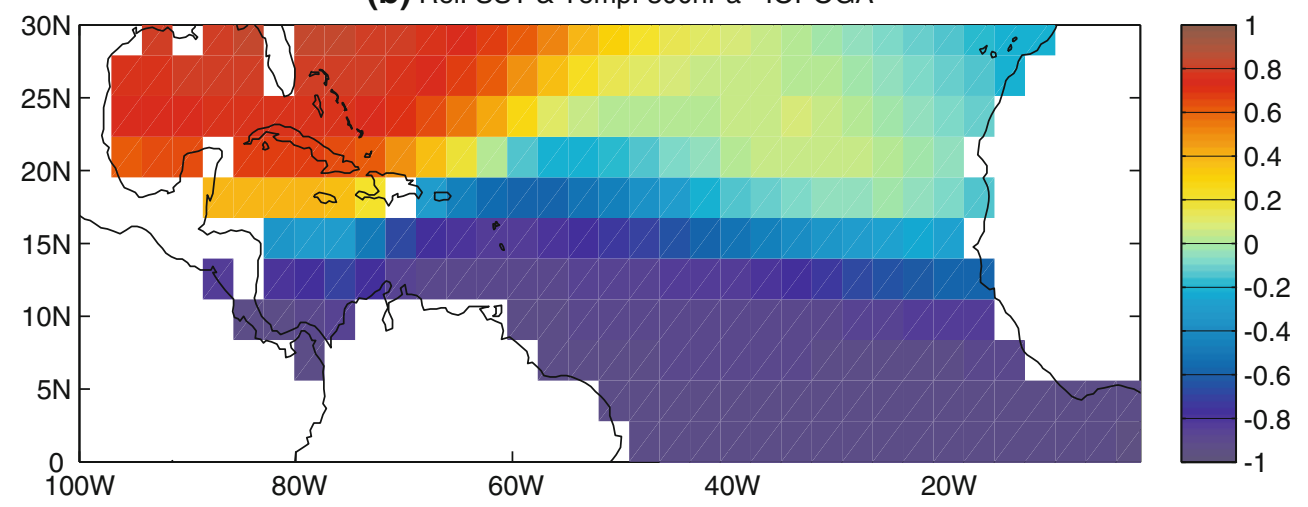


Fig. 8 a Time-series of the climate change $(\mathrm{CC})$ and AMV indices (in ${ }^{\circ} \mathrm{C}$ ) calculated following Ting et al. (2009) for the period 1900-2006.

Regression of anomalous

JJASON SST $\left({ }^{\circ} \mathrm{C}\right)$ with AMV

(b) and $\mathrm{CC}$ (c) indices per ${ }^{\circ} \mathrm{C}$ (a) CC and AMV indices

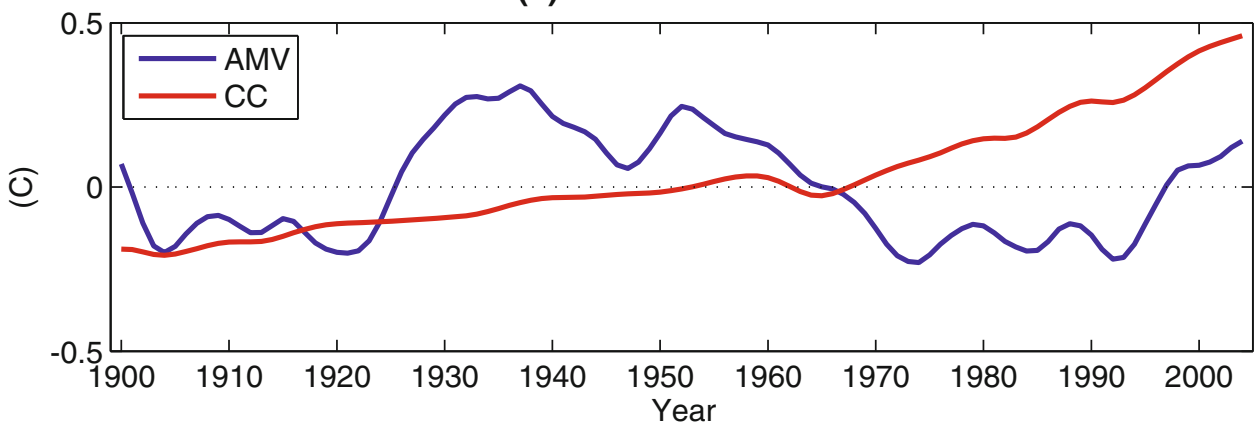

(b) Regression SST and AMV

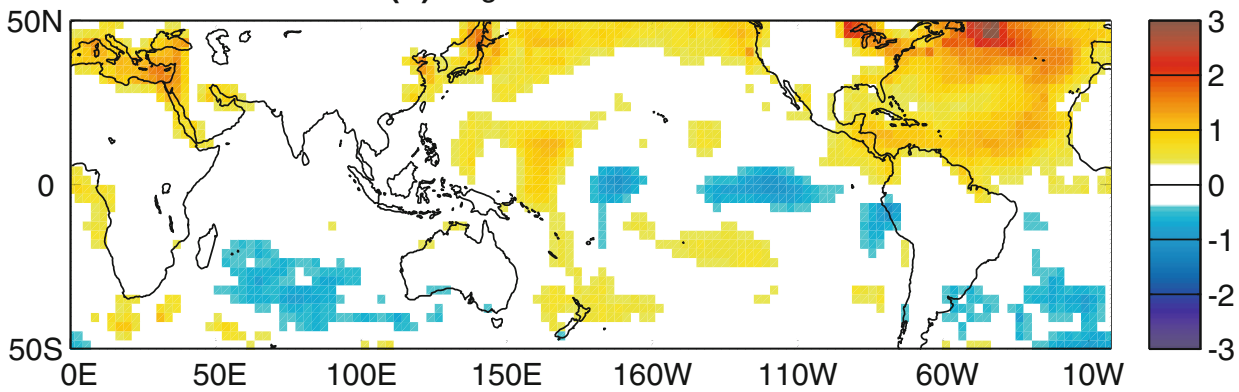

(c) Regression SST and CC

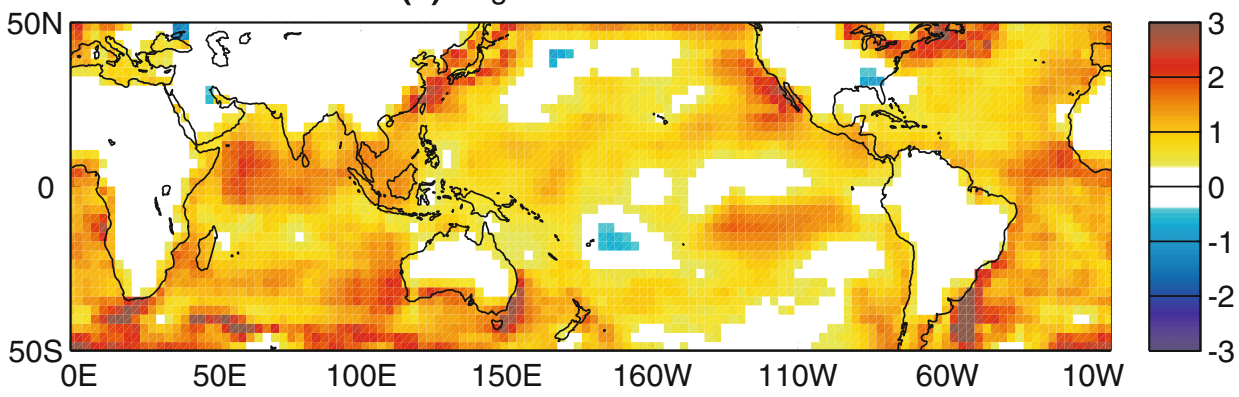

values located in the eastern tropical North Atlantic near $20^{\circ} \mathrm{N}$ and $20^{\circ} \mathrm{W}$ where the AMV-related SST values are maximum.

The maximum change in the PI patterns of GOGA and TAGA associated with the CC index (Fig. 9b, d) is located in the eastern tropical South Atlantic, consistent with the local SST anomaly maximum in the CC pattern of Fig. 8c. Large positive PI values extend northward into the Tropical North Atlantic (TNA). There is a notable difference between the TAGA and GOGA regression pattern on the CC index, with TAGA showing a much stronger positive anomaly for the TNA region than that for in GOGA. The difference between GOGA and TAGA, as shown in Fig. 9h, is largely explained by the PI regression to CC in IOPOGA (Fig. 9f). This implies that the remote SST anomalies (tropical Indian and Pacific Oceans) suppress tropical Atlantic PI anomalies associated with global warming, consistent with Vecchi et al. (2008).
While the AMV-related PI differences between GOGA and TAGA (Fig. 9g) are much smaller than the corresponding one for CC-related PI differences (Fig. 9h), it also shows a suppression of PI anomalies by remote SST. This difference in Fig. 9g is largely, but not entirely, consistent with the AMV-related PI in IOPOGA, possibly due to the weak tropical Pacific SST in Fig. 8b. However, the suppression of AMV-related, tropical Atlantic PI is larger in (Fig. 9e) is larger than expected from IOPOGA (Fig. 9g), particularly over the northeastern part of the TNA. We will address this difference and its probable cause later (see Sect. 3.4 below). The difference in PI anomalies associated with AMV between GOGA (Fig. 9a) and TAGA (Fig. 9c), however, is much smaller than the corresponding PI anomalies associated with climate change.

The regressed time-series of the TNA and MDR averaged PI onto the North Atlantic SST indices (Fig. 10a), which includes both the climate change and AMV 
(a) GOGA PI \& AMV
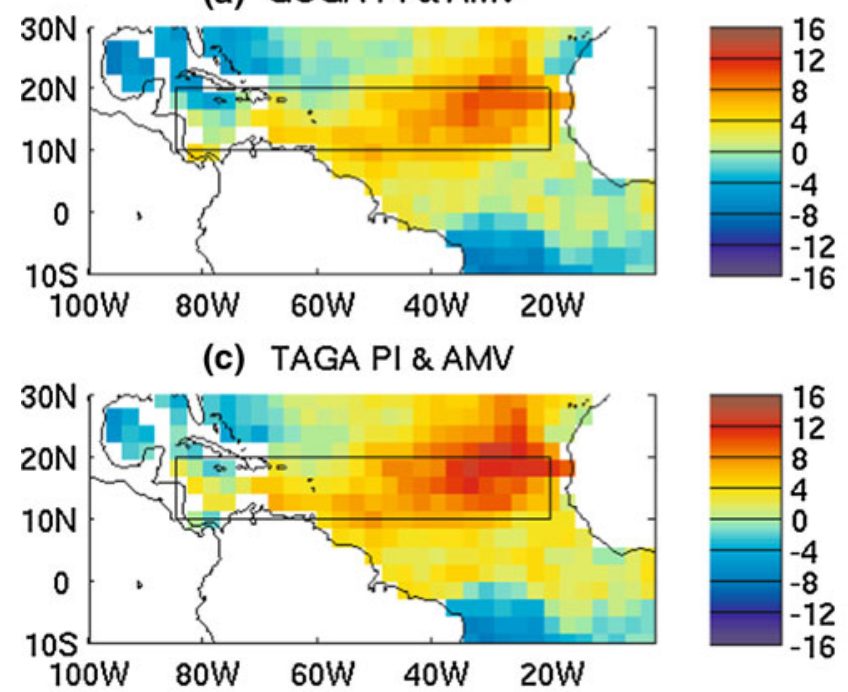

(e) IOPOGA PI \& AMV

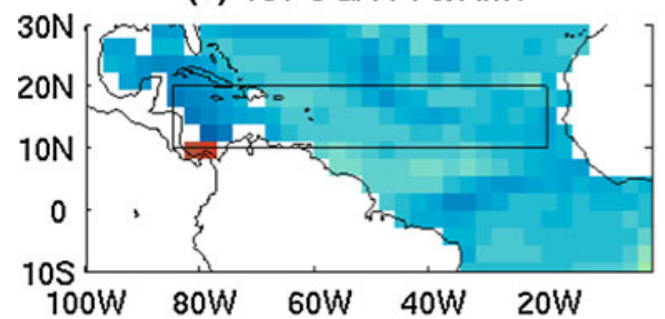

(g) Diff. GOGA \& TAGA AMV

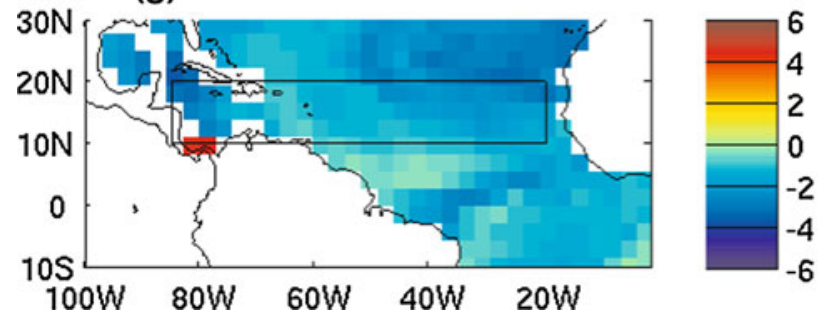

Fig. 9 Regression of anomalous ASO PI $(\mathrm{m} / \mathrm{s})$ with AMV (left panels) and climate change (CC) indices (right panels). Regression pattern of AMV and GOGA (a), TAGA (c), and IOPOGA (e). Regression pattern of CC index and GOGA (b), TAGA (d), and

components, exhibit both an upward trend and multi-decadal variations, with a larger amplitude in the case of TAGA than in GOGA. In contrast, IOPOGA has a clear downward trend in the same period. When we consider separately the impact of AMV and climate change on MDR PI (Fig. 10b, c), it is clear that both contributed to the lower values of PI in the early twentieth century and the increase in the late twentieth century and early twenty-first century for GOGA and TAGA. As expected, the AMV caused below normal PI values between 1970 and the early 1990s (as argued also in Goldenberg et al. 2001). The sum of TAGA and IOPOGA time-series (shown in black dashed line) is very close to the time-series of GOGA in all 3 panels, which confirming that the influence of the remote (b) GOGA PI \& CC

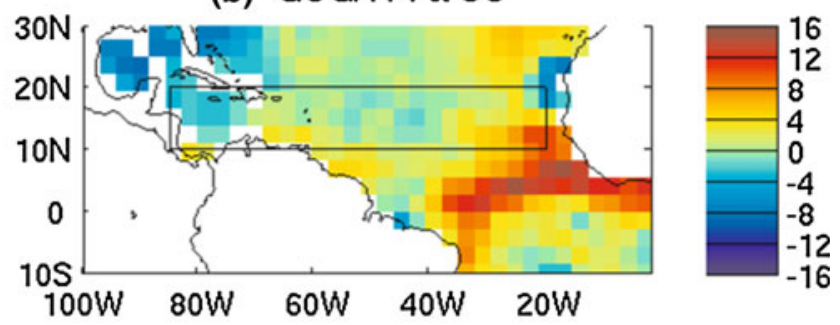

(d) TAGA PI \& CC

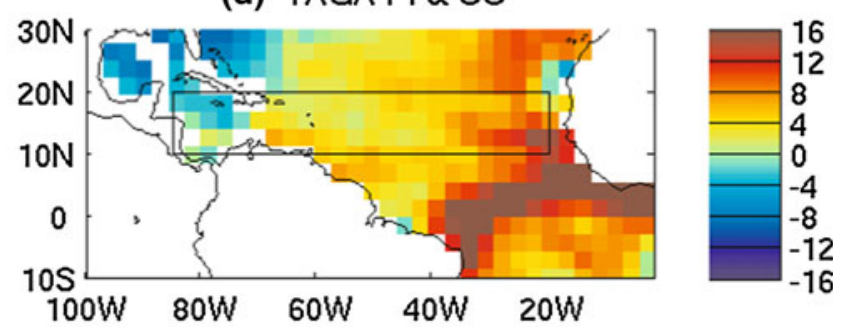

(f) IOPOGA PI \& CC

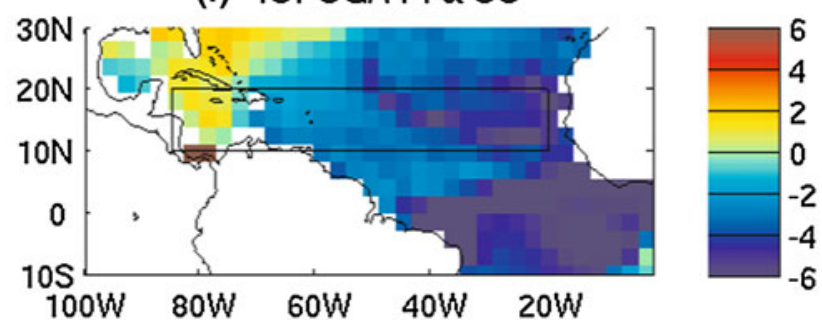

(h) Diff. GOGA \& TAGA CC

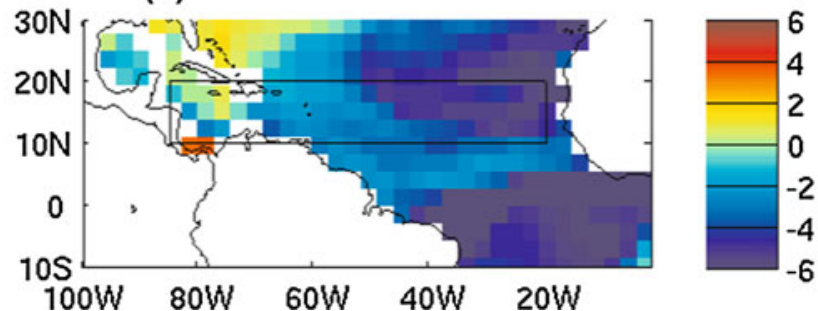

IOPOGA (f). The difference between the PI regression patterns in GOGA and TAGA are shown in (g) and (h) for the AMV and CC patterns, respectively. The region of the MDR is indicated by the black box

tropical SST in the North Atlantic PI. It is very clear in these figures that the presence of the non-local SST in GOGA (i.e. the forcing in IOPOGA) leads to weaker PI anomalies in GOGA than in TAGA, in all cases, particularly in the case of external, climate change forcing.

The results in Figs. 9 and 10 illustrate the relative importance of internal variability versus externally forced climate change in the PI of Atlantic hurricanes. Based on the results of TAGA with only the tropical Atlantic SST effects (Fig. 9c, d), and red lines in Fig. 10), the variation due to externally forced and natural PI variability is comparable (ranging between $\sim 2$ and $2.5 \mathrm{~m} / \mathrm{s}$ ). When the remote SST effects are taken into consideration in the case of GOGA (Fig. 9a, b, and blue lines in Fig. 10), the relative 
Fig. 10 Regression time-series of anomalous ASO PI $(\mathrm{m} / \mathrm{s})$ in the MDR with a AMV and CC indices, $\mathbf{b}$ AMV index component only, c CC index component only, for GOGA (blue), TAGA (red) and IOPOGA (green). Also shown in a thin dashed line is the sum of TAGA and IOPOGA (a) Anom. PI Reg. AMV \& CC

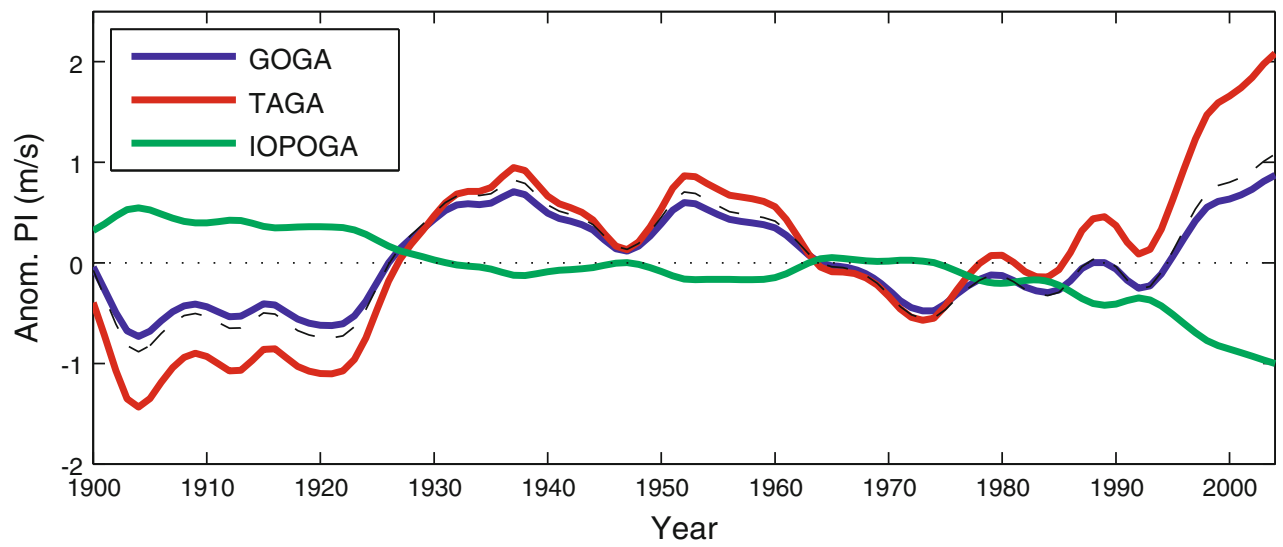

(b) Anom. PI Reg. AMV

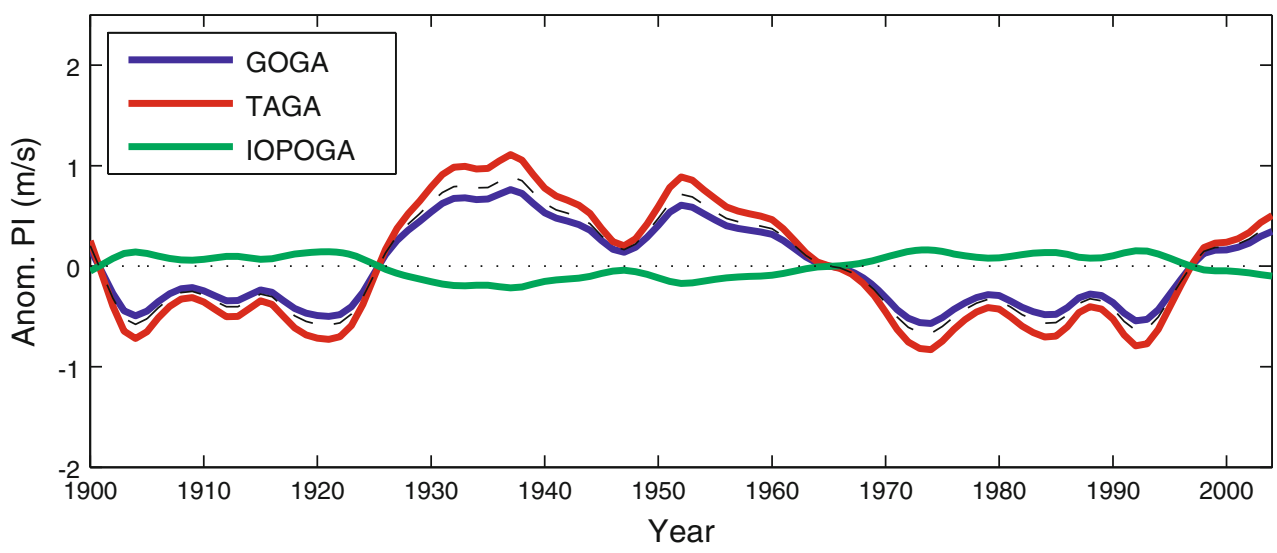

(c) Anom. PI Reg. CC

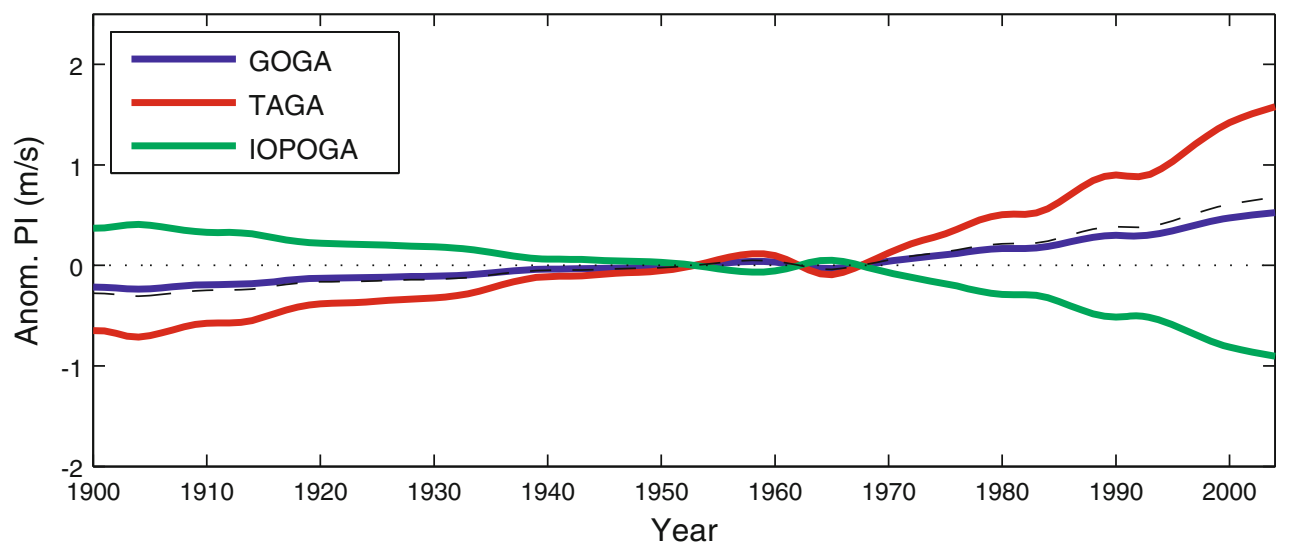

amplitude of the forced change in PI $(0.5 \mathrm{~m} / \mathrm{s})$ is much smaller than that due to the AMV $(\sim 1.5 \mathrm{~m} / \mathrm{s})$. These differences are very close to the values of the IOPOGA changes, which have the opposite sign of TAGA. The dramatic recent increases in PI (from 1990 to 2005, Fig. 1) reflects a combination of a gradual increase in PI due to forced tropical SST warming, as well as the more dramatic, late twentieth century warming due to the AMV.

\subsection{Effects of the extra-tropical North Atlantic}

As indicated above, the difference between GOGA and TAGA on the AMV response (Fig. 9e) indicates that remote ocean influences mildly suppress the local SST influence on PI even in the case of natural variability. Part of this impact is due to the slight warming in SST associate with AMV as this phenomenon is depicted in the 
observations as indicated by the difference IOPOGA and TAGA (Fig. 9g) but note that this remote association, while apparently statistically significant should be treated with some caution but that is nonetheless present in the prescribed SST fields used in this study). However, the difference GOGA-TAGA displays a large suppression of PI than the difference IOPOGA-TAGA. We suspect that this difference is due to the concomitant AMV SST change in the extratropical North Atlantic. To test this assertion, we examine a set of "idealized" simulations in which fixed Atlantic SST anomalies patterns were added to the climatological state in the Atlantic basin only. As described in Sect. 2, the anomalous SST patterns are derived from a rotated EOF analysis of the global SST in the twentieth century (as described in Schubert et al. 2009). One of the leading EOFs has pattern similar to the SST anomaly associated with AMV, and is the one considered here. The model was forced with this AMV pattern added to and subtracted from the monthly varying global SST climatology, hereafter referred to as warm AMV and cold AMV, respectively. We performed two sets of these experiments, one where the pattern was prescribed in its entirety, that is over the entire North Atlantic and the other with only the tropical portion of the pattern (between the equator and $30^{\circ} \mathrm{N}$ ) prescribed while the extratropical part is set to zero.

Figure 11 shows the difference in PI between the warm and cold AMV simulations with SST anomalies prescribed in the entire North Atlantic (a) and in the tropical Atlantic only (b). The difference between the two fields is shown in Fig. 11c. These results show that the extra-tropical North Atlantic portion of the AMV introduces a mild negative influence on the tropical Atlantic PI field. This is consistent with the stronger PI suppression GOGA-TAGA (Fig. 9g) than in IOPOGA-TAGA (Fig. 9e) discussed earlier. Assuming then that the influences are of different ocean basins are close to linear, we conclude on the basis of these fixed SST anomaly experiments that the extratropical warming (or cooling) associated with the AMV mildly counteracts the response of tropical Atlantic PI to local SST anomalies. Similar to the changes in remote tropical SSTs, the warming in the North Atlantic, which is part of the AMV SST footprint, slightly warms the tropical Atlantic upper troposphere (not shown) and thus increases the atmospheric stability of the tropics, reducing the PI in the warm AMV phase (and increases in the cold phase) relative to the impact of tropical SSTs alone.

\section{Summary}

In this paper we explore the relative importance of externally forced (mainly anthropogenic) and internal (AMV) SST variability on the tropical Atlantic tropical cyclone potential intensity, with a focus on the relative contributions of local and remote SSTs. This is achieved by using NCAR CCM3 model simulations with prescribed historical SST in the entire global ocean (GOGA), in the tropical Atlantic only (TAGA) and in the tropical Indian and Pacific Oceans only (IOPOGA). We find that the relative contribution of the forced and internal SST variability on tropical Atlantic PI depends on whether local or global SST anomalies are considered. When non-local SST effects are taken into account, the relative role of global climate change in tropical Atlantic PI, during the twentieth Century, is lower compared to that induced by the warming of

(a) Diff. PI Warm \& Cold Atlantic

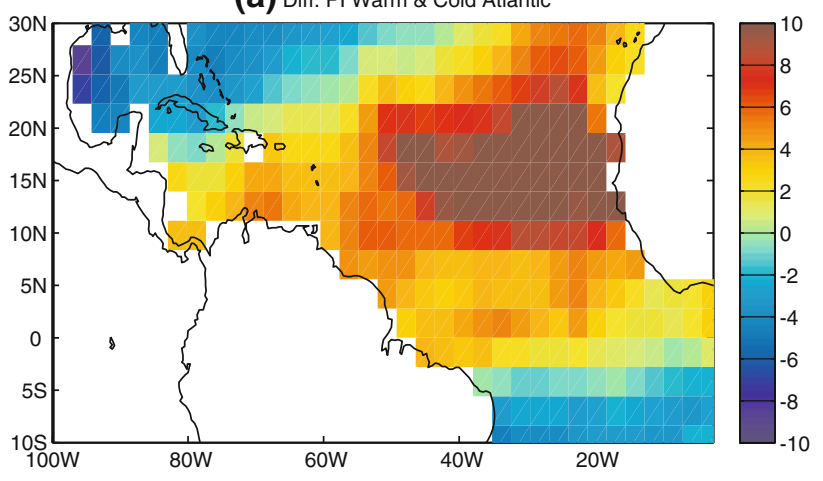

(b) Diff. PI Warm \& Cold tropical Atlantic

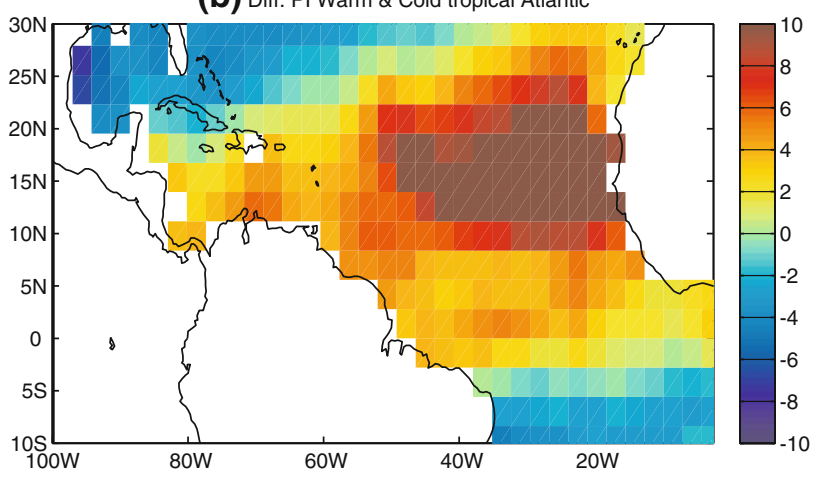

(c) Diff. PI Atlantic and Tropical Atlantic

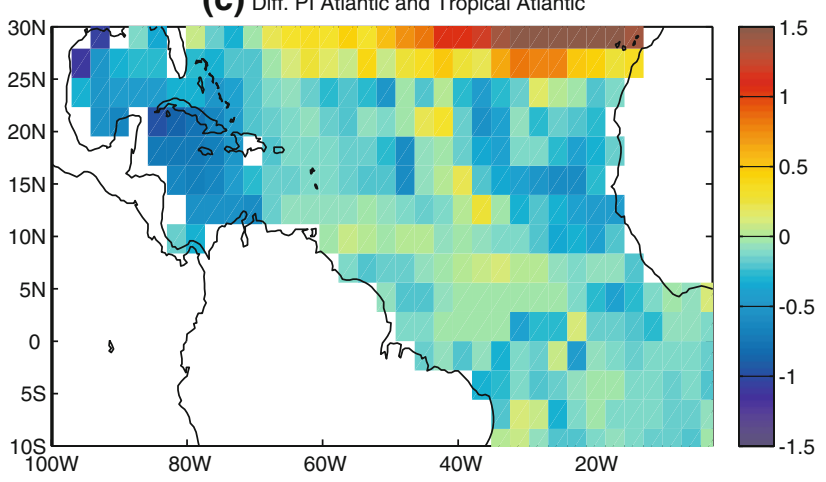

Fig. 11 Difference of PI for JJASON between: a warm and cold Atlantic, b warm and cold tropical Atlantic, c panels (a) and (b); i.e. the difference of warm and cold Atlantic minus the difference of warm and cold tropical Atlantic 
tropical Atlantic SST alone, because of the damping of the PI, resulting from the warming in the other (tropical) ocean basins. This is consistent with the idea of relative SST (local minus tropical mean) contribution to PI as discussed in Vecchi and Soden (2007) in reference to the change in hurricane potential intensity for the twenty-first century. We show here that when only the SST in the Indian and tropical Pacific Oceans is varying, with the Atlantic SSTs fixed at climatological values, the PI in the tropical Atlantic has a downward trend. The sum of the PI anomalies in the other tropical Oceans and in the Atlantic oceans is very close to the values obtained when the model is forced with global SST, pointing towards an almost linear additive behavior.

In the case of AMV, the dominant SST anomalies are located in the tropical and extra-tropical North Atlantic with a minor contribution from other ocean basins. The PI variations associated with the AMV are thus largely determined by the local SST change. The dominance of local SST in the AMV case leads us to conclude that the late twentieth Century increase in North Atlantic PI (e.g. Kossin and Camargo 2009), while closely related to the tropical Atlantic SST increase (Fig. 1), includes a considerable impact of internal variability and cannot be attributed purely to anthropogenic warming. The up swing of the multi-decadal internal SST variability associated with AMV is the most important cause (as hinted also by results of DelSole et al. 2011). Whether and how PI may change in the late 21 st century, when anthropogenic influence increases in amplitude while the AMV can presumably continue to slowly swing between negative and positive phases with the same amplitude as during the twentieth Century (see Ting et al. 2011) will be examined in a subsequent study using the CMIP3 and CMIP5 simulations.

Recent papers by Emanuel $(2010,2012)$ analyzed the relative influence of tropical tropopause layer cooling in the Atlantic on potential intensity trends in models and observations and emphasized that the climate models shortcomings in simulating this cooling could be significant. However, Vecchi (2012) did not show the same level of sensitivity to this cooling in the high-resolution climate model analyzed. Regardless, we should note that the relative importance of the tropopause cooling over the Atlantic was not considered explicitly in our analysis.

Acknowledgments The authors acknowledge support of the National Oceanic and Atmospheric Administration (NOAA) Grants NA08OAR4320912, NA10OAR4310124 and NA10OAR4320137. We would like to thank Donna Lee and Naomi Naik (LDEO) for performing the CCM3 simulations used in this study. The authors would like to thank the Global Decadal Hydroclimate group at Lamont and Columbia for helpful discussion and input and two anonymous reviewers for their useful suggestions and comments.

\section{References}

Bister M, Emanuel KA (1998) Dissipative heating and hurricane intensity. Meteor Atmos Phys 65:223-240

Bister M, Emanuel KA (2002a) Low frequency variability of tropical cyclone potential intensity: 1 . Interannual to interdecadal variability. J Geophys Res 107:4801. doi:10.1029/2001JD000776

Bister M, Emanuel KA (2002b) Low frequency variability of tropical cyclone potential intensity: 2. Climatology for 1982-1995. J Geophys Res 107:4621. doi:10.1029/2001JD000780

Bryan GH, Rotunno R (2009) The maximum intensity of tropical cyclones in axisymmetric numerical model simulations. Mon Weather Rev 137:1770-1789

DelSole T, Tippett MK, Shukla J (2011) A significant component of unforced multidecadal variability in the recent acceleration of global warming. J Clim 24:909-926

Emanuel KA (1986) An air-sea interaction theory for tropical cyclones. Part I: steady-state maintenance. J Atmos Sci 43:585-604

Emanuel KA (1987) The dependence of hurricane intensity on climate. Nature 326:483-485

Emanuel KA (1988) The maximum intensity of hurricanes. J Atmos Sci 45:1143-1155

Emanuel KA (1995) Sensitivity of tropical cyclones to surface exchange coefficients and a revised steady-state model incorporating eye dynamics. J Atmos Sci 52:3969-3976

Emanuel K (2005) Increasing destructiveness of tropical cyclones over the past 30 years. Nature 436:686-688

Emanuel K (2010) Tropical cyclone activity downscaled from NOAA-CIRES Reanalysis, 1908-1958. J Adv Model Earth Syst 2. doi:10.3894/JAMES.2010.2.1

Emanuel K, Solomon S, Folini D, Davis S, Cagnazzo C (2012) Influenced of tropical tropopause layer cooling on Atlantic hurricane activity. J Clim (submitted)

Enfield DB, Mestas-Nunez AM, Trimble PJ (2001) The Atlantic multidecadal oscillation and it's relation to rainfall and river flows in the continental U.S. Geophys Res Lett 28:2077-2080

ERA-Interim (2011) ERA-Interim re-analysis brief description, http://www.ecmwf.int/research/era/do/get/ERA-Interim_brief

Goldenberg SB, Landsea CW, Mestas-Nuñez AM, Gray WM (2001) The recent increase in Atlantic hurricane activity: causes and implications. Science 293:474-479

Graumann A, Houston T, Lawrimore J, Levinson D, Lott N, McCown S, Stephens S, Wuertz D (2005) Hurricane Katrina-a climatological perspective. NOAA's National Climatic Data Center, Technical Report 2005-01

Gray WM (1968) Global view of the origin of tropical disturbances and storms. Mon Weather Rev 96:669-700

Gray WM (1979) Hurricanes: their formation, structure and likely role in the tropical circulation. Meteorology over the tropical oceans. Royal Meteorological Society, Bracknall

Holland GJ (1997) The maximum potential intensity of tropical cyclones. J Atmos Sci 54:2519-2541

Kalnay E et al (1996) The NCEP/NCAR 40-year reanalysis project. Bull Am Meteorol Soc 77:437-471

Kaplan A, Cane MA, Kushnir Y, Clement AC, Blumenthal MB, Rajagopalan B (1998) Analyses of global sea surface temperature: 1856-1991. J Geophys Res 103:18567-18589

Kiehl JT, Hack JJ, Bonan GB, Bovile BA, Williamson DL, Rasch PJ (1998) The national center for atmospheric research community climate model: CCM3. J Clim 11:1131-1149

Kistler R et al (2001) The NCEP-NCAR 50-year reanalysis: monthly means CD-ROM and documentation. Bull Am Meteorol Soc $82: 247-267$

Kossin JP, Camargo SJ (2009) Hurricane track variability and secular potential intensity trends. Clim Chang 9:329-337 
Kossin JP, Vimont DJ (2007) A more general framework for understanding Atlantic hurricane variability and trends. Bull Am Meteorol Soc 88:1767-1781

Kossin JP, Camargo SJ, Sitkowski M (2010) Climate modulation of North Atlantic hurricane tracks. J Clim 23:3057-3076

Kushnir Y (1994) Interdecadal variations in North Atlantic Sea surface temperature and associated atmospheric conditions. J Clim 7:141-157

Kushnir Y, Seager R, Ting M, Naik N, Nakamura J (2010) Mechanisms of tropical Atlantic SST influence on North American precipitation variability. J Clim 23:5610-5628

Lau N-G, Nath MJ (1994) A modeling study of the relative roles of tropical and extratropical SST anomalies in the variability of the global atmosphere-ocean system. J Clim 7:1184-1207

Mann ME, Emanuel KA (2006) Atlantic hurricane trends linked to climate change. EOS. Trans Am Geophys Union 87:233-241

Montgomery MT, Van Sang N, Smith RK, Persing J (2009) Do tropical cyclones intensify by WISHE? Q J R Meteorol Soc 135:1697-1714

Palmén EH (1948) On the formation and structure of tropical cyclones. Geophysica 3:26-38

Ramsay HA, Sobel AH (2011) Effects of relative and absolute sea surface temperature on tropical cyclone potential intensity using a single-column model. J Clim 24:183-193

Rayner N, Parker D, Horton E, Folland C, Alexander L, Rowell D, Kent E, Kaplan A (2003) Global analyses of sea surface temperature, sea ice, and night marine air temperature since the late nineteenth century. J Geophys Res 108:4407. doi: 10.1029/2002JD002670

Schubert S et al (2009) A US CLIVAR project to assess and compare the responses of global climate models to drought-related SST forcing patterns: overview and results. J Clim 22:5251-5272

Seager R (2007) The turn of the century North American drought: global context, dynamics, and past analogs. J Clim 20:5527-5552

Seager R, Kushnir Y, Herweijer C, Naik N, Velez J (2005) Modeling of tropical forcing of persistent droughts and pluvials over western North America: 1856-2000. J Clim 18:4065-4088

Seager R, Kushnir Y, Ting M, Cane M, Naik N, Miller J (2008) Would advance knowledge of 1930s SSTs have allowed prediction of the dust bowl drought? J Clim 21:3261-3281

Servain J (1991) Simple climatic indexes for the tropical AtlanticOcean and some applications. J Geophys Res C 96:15137-15146
Smith RK, Montgomery MT, Vogl S (2008) A critique of Emanuel's hurricane model and potential intensity theory. Quart J R Meteorol Soc 134:551-561

Sobel AH, Camargo SJ (2012) Projected future seasonal changes in tropical summer climate. J Clim 24:473-487

Sobel AH, Held IM, Bretherton CS (2002) The ENSO signal in tropical tropospheric temperature. J Clim 12:2702-2706

Solomon A, Goddard L, Kumar A, Carton J, Deser C, Fukumori I, Greene AM, Hegerl G, Kirtman B, Kushnir Y, Newman M, Smith D, Vimont D, Delworth T, Meehl GA, Stockdale T (2011) Distinguishing the roles of natural and anthropogenically forced decadal climate variability. Bull Am Meteorol Soc 92:141-156

Swanson KL (2008) Nonlocality of tropical cyclone intensities. Geochem Geophys Geosyst 9:Q04V01

Tang BH, Neelin JD (1994) ENSO influence on Atlantic hurricanes via tropospheric warming. Geophys Res Lett 31:L24204

Ting M, Kushnir Y, Seager R, Li C (2009) Forced and natural 20th Century SST trends in the North Atlantic. J Clim 22:1469-1481

Ting M, Kushnir Y, Seager R, Li C (2011) Robust features of Atlantic multidecadal variability and its climate impacts. Geophys Res Lett 38:L17705. doi:10.1029/2011GL048712

Uppala SM et al (2005) The ERA-40 re-analysis. Quart JR Meteorol Soc 131:2961-3012

Vecchi GA, Soden BJ (2007) Effect of remote sea surface temperature change on tropical cyclone potential intensity. Nature 450:1066-1070

Vecchi GA, Swanson KL, Soden BJ (2008) Whither hurricane activity? Science 322:687-689

Vecchi GA, Fueglistaler S, Held IM, Knutson TR, Zhao M (2012) Influence of tropical tropopause layer cooling on Atlantic hurricane activity. J Clim (submitted)

Villarini G, Vecchi GA (2012) Twenty-first-century projections of North Atlantic tropical storms from CMIP5 models. Nat Clim Chang Early online. doi:10.1938/nclimate1530

Vimont DJ, Kossin JP (2007) The Atlantic meridional mode and hurricane activity. Geophys Res Lett 34:L07709

Wing AA, Sobel AH, Camargo SJ (2007) The relationship between the potential and actual intensities of tropical cyclones on interannual time scales. Geophys Res Lett 34:L08810

Zhang R, Delworth TL (2006) Impact of Atlantic multidecadal oscillation on India/Sahel rainfall and Atlantic hurricanes. Geophys Res Lett 33:L17712 